\title{
Reconceptualizing the Role of Fear of Falling and Balance \\ Confidence in Fall Risk
}

\author{
Thomas Hadjistavropoulos ${ }^{1}$ \\ Kim Delbaere ${ }^{2,3,4}$ \\ Theresa Dever Fitzgerald ${ }^{1}$
}

${ }^{1}$ Centre on Aging and Health and Department of Psychology, University of Regina, Canada

${ }^{2}$ Falls and Balance Research Group, Prince of Wales Medical Research Institute, University of New South Wales, Randwick, Sydney, Australia

${ }^{3}$ Department of Experimental-Clinical and Health Psychology, Faculty of Psychology and Educational Sciences, Ghent University, Belgium

${ }^{4}$ Department of Rehabilitation Sciences and Physiotherapy, Faculty of Medicine and Health Sciences, Ghent University, Belgium

We thank the editor, Dr. Kyriakos Markides, for inviting this manuscript. Direct

correspondence to Thomas Hadjistavropoulos, Ph.D., ABBP, FCAHS, Department of Psychology, University of Regina, Regina, SK, Canada, S4S 0A2 email:

hadjistt@uregina.ca 


\begin{abstract}
Objective: We aimed to critically examine pre-existing conceptualizations of the relationship among fear of falling, falls efficacy and falls and to offer a new theoretical model incorporating findings from the recent literature. Methods: This a theoretical paper based on a review of pre-existing findings pertaining to fear of falling and falls efficacy. Discussion: Traditional conceptualizations consider avoidance of activity and deconditioning to be mediators in the relationship between fear of falling and falls but recent findings suggest that this mediational conceptualization may not be accurate. Moreover, the terms "falls efficacy" and "fear of falling" are often used interchangeably in the literature, which is conceptually problematic. We conclude with the presentation and discussion of an alternative predictive model of fear of falling that incorporates important findings from the recent literature.
\end{abstract}

Key words: accidental falls, elderly, older adults, aging, falls efficacy 
Falling is a high risk event for seniors and, as a result, older persons require a disproportionately high number of resources for trauma care (Rice \& MacKenzie, 1989). Approximately one in three older adults will experience a fall annually, and approximately half of these individuals will experience more than one fall per year (Hawk, Hyland, Rupert, Colonvega, \& Hall, 2006). Falls represent one of the leading causes of injury-related hospitalization and injury-related death for older adults. Moreover, the rate of injury and hospitalization doubles in seniors over the age of 75 (Rubenstein, 2006). Stevens et al. (2006) indicate that $31.3 \%$ of falls reported in the United States, over a one year period, resulted in: a) An injury requiring a visit to the physician; and b) at least one day of restricted activity. This restriction of activity can reduce the quality of life and increase dependence on others (Murphy, Dubin, \& Gill, 2003).

Given the serious consequences of falls, it is not surprising that fear of falling has been reported in $50-60 \%$ of reported fallers in several community samples (Legters, 2002). Between $25-33 \%$ of these fearful individuals acknowledge avoidance of activity because of fear of falling (Legters, 2002). Excessive fear of falling, often referred to as the "post-fall syndrome" (Murphy \& Isaacs, 1982), can lead to activity restriction and loss of independence beyond that warranted by physical injuries resulting from the fall itself (Vellas, Wayne, Romero, Baumgartner, \& Garry, 1997). Nonetheless, fear of falling is also found in many seniors who have not experienced any fall episodes or related injuries (Legters, 2002).

Interestingly, fear of falling (Delbaere, Crombez, Vanderstraeten, Willems, \& Cambier, 2004; Friedman, Munoz, West, Rubin, \& Fried, 2002), and falls efficacy (belief 
that one has the ability to maintain balance) (Cumming, Salkeld, Thomas, \& Szonyi, 2000; Hadjistavropoulos et al., 2007), have been found to be predictive of future falls (Cumming et al., 2000; Friedman et al., 2002). In addition, elevated fear of falling has been linked to reduced leaning balance (Delbaere et al., 2004) and an impaired, 'cautious' gait (Delbaere, Sturnieks, Crombez, \& Lord, 2009). It is important to note that, to the best of our knowledge, no research group has found that fear of falling is an independent risk factor for falls after adjusting for these functional measures. This suggests that the relationship between falls and fear of falling is likely mediated by balance and gait performance.

\section{Objectives}

A clear theoretical framework of the complex construct fear of falling is lacking in the current literature. The availability of several different questionnaires and interchangeable use of different conceptualizations of fear of falling make it difficult to determine the nature of the construct, as well as who develops this fear and why. In this paper, we consider theoretical issues related to fear and avoidance within the context of fall risk for older persons. Our aims were to to (1) revisit traditionally accepted conceptualizations of fear of falling and falls efficacy in relation to falls, and (2) propose a novel, multi-component model based on published findings and improved conceptualizations of fear of falling.

\section{Methodological Approach}

We conducted a review of pre-existing findings pertaining to fear of falling and falls efficacy, aiming to combine theories from several different disciplines including kinesiology, physical therapy, and psychology. More specifically, we sought to review 
pre-existing conceptualizations aiming to explain the consequences of efficacy beliefs and fears related to falling, as well as studies examining associations of falls efficacy beliefs and fear of falling with falls, functional decline, and avoidance. Finally, we aimed to review investigations of the relationship between activity avoidance and falls. We searched the literature (through the "Pubmed" data base) using the following primary search terms: "fear of falling", "falls", "balance confidence", "falls efficacy", and "balance performance". This search was limited to human studies, English language, and persons over 60 years of age. Rather than intending to provide an exhaustive review of the literature, we have selected papers that were helpful in providing answers to the following theoretical questions:
a) Do fear and/or falls efficacy predict falls?
b) Does avoidance predict functional decline?
c) Do fear and falls efficacy predict avoidance?
d) Does avoidance predict falls?
e) Can fear and anxiety have direct influence on balance performance?
f) Can a low falls efficacy be reflective of an accurate appraisal of one's balance capabilities and fall risk?

\section{Fear of Falling and Falls Efficacy}

We view fear of falling as involving three components that do not necessarily overlap (Rachman, 1978). These components are: a) the physiological (e.g., increased autonomic reactivity); b) the behavioral (e.g., walking in a very slow speed in order to prevent a fall); and c) the cognitive (e.g., one's subjective estimation of the level of danger and ability to avoid a fall). Despite the multi-dimensional nature of fear, in most 
community studies fear of falling was assessed with paper and pencil tests that tap primarily on the cognitive aspect of fear (e.g., Austin, Devine, Dick, Prince, \& Bruce, 2007; Li, Fisher, Harmer, McAuley, \& Wilson, 2003; Zijlstra et al., 2007). In some experimental studies, Delbaere et al., (2009) and Carpenter et al., (2006) also evaluated the physiological and behavioral components through the use of psychophysiological monitoring equipment and the assessment of balance parameters. Nonetheless, these investigators did not use these indices to validate their ability to predict future falls risk, although other research has linked several gait parameters to fall risk (Verghese, Holtzer, Lipton, \& Wang, 2009). Assessing all of the three components of fear of falling (i.e., physiological, cognitive and behavioral), could lead to more accurate estimation of fall risk.

Anxiety and fear are closely related, but the two can be distinguished on a variety of elements including duration (Rachman, 1998). For example, an individual may always be fearful of a situation (e.g., flying in an airplane) but would only experience anxiety during the flight, in anticipation of an upcoming flight or in response to recollections from previous flights. Self-efficacy beliefs are also related to fear of falling in the sense that fear is affected by beliefs (Barlow, 2008). Those who are confident that they will not fall, for example, would be less likely to present with fear of falling as compared to those who believe that they would probably fall and injure themselves.

Tinetti, Richman and Powell (1990) argued that fear of falling can be conceptualized as "low perceived self-efficacy" about balance and titled their 1990 seminal article "Falls Efficacy as a Measure of Fear of Falling". Self-efficacy measures are based on social cognitive theory (Bandura, 1994) and self-efficacy in this context 
implies beliefs and confidence about one's ability to avoid a fall. Tinetti et al. noted that this conceptualization would be advantageous because self-efficacy is a concept based upon strong theoretical assumptions about the cognitive process that underlies emotions (Bandura, 1986). Therefore, many valid assessment strategies have been designed to assess self-efficacy with respect to a variety of different domains.

Moreover, Tinetti et al. argued that fear has emotional connotations implying analogy to phobias (i.e., ptophobia; Bhala, O'Donnell, \& Thoppil, 1982) which "may or may not be accurate". In addition, they argued that efficacy may be linked to functional decline since persons with low perceived self-efficacy about one activity tend to avoid that activity.

Although the Tinetti et al. original conceptualization of "falls efficacy as a measure of fear of falling" led to fruitful investigations and facilitated an extremely important area of inquiry, their encouragement of interchangeable usage of fear of falling and low falls efficacy is not theoretically sound. Consistent with the position expressed by Moore and Ellis (2008), we argue that falls-related self-efficacy (or balance confidence) and fear of falling are correlated but distinct dimensions. Selfefficacy refers to beliefs about one's own ability. It is well established that certain beliefs can lead to fear and anxiety (Barlow, 2008) without always co-occuring with anxiety. As such, it is not surprising that self-efficacy beliefs have been found to be completely unrelated to anxiety in some studies (e.g., Butki, Rudolph, \& Jacobsen, 2001). When low self-efficacy beliefs co-occur with fear, they could be construed as being related to the cognitive aspect of fear. Given the relationship between fear and beliefs (Barlow, 2008), people with low falls efficacy would be likely to present with increased fear of falling which would explain why falls efficacy and fear of falling have been found to be 
correlated (e.g., Hadjistavropoulos et al., 2007). In examining the interrelationships of falls efficacy and fear of falling, we review scales assessing these constructs as well as studies that clarify the relationship between fear and falls efficacy beliefs.

Measurement of Falls Efficacy and Fear of Falling: Over the years, several different assessment methods of fear of falling and falls efficacy have been used. Scales with good psychometric properties have been developed to measure falls efficacy (Jorstad, Hauer, Becker, \& Lamb, 2005). These scales include multiple items that assess a person's confidence in his or her ability to avoid falling while undertaking activities of daily living such as taking a bath or shower, walking around the house, and shopping. The most commonly used measure of falls efficacy is the Falls Efficacy Scale (FES; Tinetti et al., 1990). The scale has good reliability and validity (Jorstad et al., 2005), and predicts falls (Hadjistavropoulos et al., 2007). Modifications of the FES, varying in response format and somewhat expanding its range of items, have been published (Hill, Schwarz, Kalogeropoulos, \& Gibson, 1996).

Most recently, a scale was developed and validated by the Prevention of Falls Network Europe (ProFaNE) -- a European Union funded collaboration fostering international consensus with respect to research into fall prevention (Lamb, JorstadStein, Hauer, Becker, \& Preventon of Falls Network Europe and Outcomes Consensus Group, 2005). The Falls Efficacy Scale International (FES-I; Yardley et al., 2005) contains the 10 items from the original FES and 6 new items on more complex instrumental activities of daily living and social activities such as visiting friends or relatives or going to a social event. However, adding to the existing confusion, instead of assessing efficacy (as suggested by its name) it assesses levels of concern about 
falling. The FES-I has been found to be predictive of falls in longitudinal research (Delbaere et al., in press).

Myers et al. (1998) used an approach, similar to the original FES (assessing balance confidence) in developing the Activities Balance Confidence Scale (ABC) but expanded the range of items to include more complex instrumental activities of daily living (e.g., step onto or off an escalator, walk outside on icy sidewalks). The scale has good reliability and construct and validity (Jorstad et al., 2005). It is predictive, for example, of activity avoidance and falls (Hadjistavropoulos et al., 2007). Although the name of the $A B C$ scale refers to balance confidence and the FES scale refers to falls efficacy, the items in the FES and ABC are similar and appear to be measuring the same construct.

In addition to the falls efficacy measurements, several scales were also developed to assess fear of falling. The simplest assessments for fear of falling have been single questions such as "are you afraid of falling?" with yes/no (Maki, 1997; Maki, Holliday, \& Topper, 1991; Tinetti \& Powell, 1993; Tinetti et al., 1990) and graded response (Lawrence et al., 1998) formats. Taking a somewhat different approach, Lachman et al. (1998) developed the Survey of Activities and Fear of Falling in the Elderly (SAFE) measure that assessed fear of falling and also provided an index of activity avoidance due to fear. As such, unlike approaches based on the $A B C$ and the FES, the SAFE more clearly assesses the behavioral component of fear. The measure also has satisfactory reliability and validity (Jorstad et al., 2005).

Distinguishing Among Fear of Falling, Falls Efficacy and Balance Confidence: The construct of balance confidence is conceptually similar to falls efficacy. As such, the 
FES and the ABC assess very similar constructs and show high correlations (e.g., .86) with one another (Hotchkiss et al., 2004). In contrast, correlations of falls efficacy with fear of falling measures are considerably lower (Hotchkiss et al., 2004). Given the similarity of items designed to measure falls efficacy and balance confidence (e.g., both the $A B C$ and FES questions are about the extent to which the person is confident that he or she can perform day-to-day activities without falling), as well as the high correlation of balance confidence and falls efficacy measures, we consider the two constructs to be equivalent.

In a study of pain-related fear (as opposed to falls-related fear), it was found that functional self-efficacy (i.e., self-efficacy concerning one's ability to engage in functional activities) mediates the relationship between pain-related fear and disability. In fact, after controlling for pain-related fear, self-efficacy beliefs have been found to explain an additional $24 \%$ of the variance in disability (Denison, Asenlof, \& Lindberg, 2004). Within the falls literature, Li et al. (2002) demonstrated that falls efficacy (measured using the $A B C$ ), mediated the relationship between fear of falling (measured using the SAFE) and functional ability. Moreover, the contribution of falls efficacy to the prediction of functional ability was stronger than the contribution of fear of falling (Li et al., 2002). In addition, Hadjistavropoulos et al. (2007) demonstrated that fear of falling (measured using the SAFE) also was a better predictor of activity level than falls efficacy (measured using the $A B C$ and the FES). On the other hand, falls efficacy was a better predictor of falls than fear of falling. This supports the distinctiveness of the two constructs. 
In sum, the literature supports the notion that there are conceptual problems with equating fear of falling with falls efficacy and demonstrates that the two constructs are distinct but related. Fear of falling and falls efficacy should not be used interchangeably and falls efficacy is a mediator in the relationship between fear of falling and falls. In the discussion that follows we use the term "falls efficacy" in order to ensure consistency in terminology but we consider the term "balance confidence" to be equivalent and interchangeable with the term "falls efficacy".

Fear and Avoidance in Relation to Falls

One very important behavioral component of fear of falling is self-restricted avoidance of activities, which has led to the formulation of a vicious circle or negative spiral towards frailty and decreased independence. A clear theoretical framework on the relation between fear of falling and activity avoidance is lacking in the current literature. Nonetheless, fear-avoidance models of pain have been proposed and investigated largely in cross-sectional studies of younger adults (Asmundson \& Taylor, 1996; Asmundson, Vlaeyen, \& Crombez, 2004; Norton \& Asmundson, 2003). Investigations involving older persons have only begun to emerge (Martin, Hadjistavropoulos, \& McCreary, 2005; Williams, Hadjistavropoulos, \& Asmundson, 2005).

According to the fear-avoidance model of pain (Lethem, Slade, Troup, \& Bentley, 1983), fear, anxiety, and related appraisals around pain and injury can lead to avoidance of beneficial activity among some patients and eventually to deconditioning, stiffening as well as increased chronicity of the pain problem (Asmundson \& Wright, 2004). Fear-avoidance models of pain involve physiological, behavioral, and cognitive aspects of learning and performance (Vlaeyen \& Linton, 2000). Although the role of 
beliefs and cognitions in fear and avoidance is recognized in fear avoidance models of pain, classical conditioning processes and, more specifically, associations of specific neutral stimuli (e.g., to bend, lift, work) with pain, result in avoidance of a potentially threatening situation. The short-term success of avoidance in reducing experiences of anxiety, fear, and pain negatively reinforces a self-perpetuating fear-avoidance cycle.

A similar conceptual approach has also been prominent in the literature focusing on falls in older persons (Brummel-Smith, 1989). According to such models of falls, fear of falling can lead to excessive activity restriction which would in turn lead to muscle atrophy, poor balance, impaired gait, physical deconditioning and, ultimately, falls (see Figure 1). These models, therefore, suggest that the negative impact of fear of falling on physical functioning and falls, is mediated through a self-imposed activity restriction. Inactivity is known to impact negatively on falls, poor health, and physical frailty. Additionally, a similar pathway could explain the impact of fear of falling on other psychological constructs such as quality of life, depression and social isolation.

Interestingly, activity restriction appears to be affected, in part, by social support (Howland et al., 1998). People with good social support networks who talk with friends about fall-related concerns are least likely to report activity curtailment. Wright et al., (1990), concluded that fears (as assessed through qualitative analysis of narrative discussion data) centering around falling were related to fears of being transferred to highly dependent nursing home units and fear of being restrained (e.g., belted in a wheel chair). Indeed, falls have been found to be a factor in $40 \%$ of nursing home admissions (Kellogg International Work Group on the Prevention of Falls by the Elderly, 1987). Since the availability of support is a factor determining whether 
institutionalization will occur, those who cannot rely on family and friends may feel particularly vulnerable to losing their independence (Howland et al., 1998).

Critical Examination of the Traditional Fear Avoidance Model of Falling

Despite relevant advances in the literature over the last 20 years, traditional fearavoidance conceptualizations of falls are accepted with minimal criticism. In contrast, fear-avoidance models of pain have been modified to reflect new trends and findings in the literature (e.g., Asmundson \& Wright, 2004). Appraisal and cognitive expectancies have become more important and avoidance is viewed as preventing information acquisition that would disconfirm inaccurate beliefs about the relationship between pain and activity. We review evidence for fear avoidance models of falls as well as related research and theoretical questions that can be raised. In examining the validity of traditional fear-avoidance conceptualizations of falls, we ask some basic questions to assess the validity of the various model paths.

Do fear and falls efficacy predict falls? Indeed, fear of falling and falls efficacy have both been associated with both previous falls (Arfken, Lach, Birge, \& Miller, 1994; Fletcher \& Hirdes, 2004; Lachman et al., 1998) and future falls (Cumming et al., 2000; Hadjistavropoulos et al., 2007; Murphy et al., 2003; Murphy, Williams, \& Gill, 2002).

Does avoidance predict functional decline? Physical inactivity as a result of fearavoidance of activities can lead to physical deconditioning and frailty (Delbaere et al., 2004). A sedentary lifestyle can result in a faster deterioration of musculoskeletal and sensory systems than seen in normal aging, and can, therefore, result in increased muscle atrophy as well as decreased neuromuscular coordination. As such, through 
deconditioning, fear of falling could result in poorer postural stability and, consequently, in increased probability of sustaining falls and fall-related injuries.

Do fear and falls efficacy predict avoidance? The relationship between activity avoidance and fear of falling and falls efficacy is quite well established (Howland et al., 1998; Howland et al., 1993; Jorstad et al., 2005; Petrella, Payne, Myers, Overend, \& Chesworth, 2000; Tinetti, Deleon, Doucette, \& Baker, 1994). Consistent with predictions of fear-avoidance models, Li et al. have demonstrated that individuals with higher fear scores on the SAFE engaged in fewer activities than individuals who did not report a fear of falling when performing activities (Li et al., 2003). According to Buer and Linton (2002) (pain literature), this could then result in more difficulty performing ADLs. Similarly, Delbaere et al. (2009), showed that scores on the FES-I are associated with a decline in ADLs. However, due to the cross-sectional design and the correlational nature of the results, the direction of this relationship cannot be determined with certainty.

Does Avoidance Predict Falls? Although fear of falling and falls efficacy are related to both falls (e.g., Delbaere et al., 2004; Hadjistavropoulos et al., 2007) and avoidance (e.g., Fessel \& Nevitt, 1997), there is a paucity of investigations examining the ability of avoidance to predict falls, despite evidence that excessive avoidance can lead to deconditioning (Arfken et al., 1994; Bruce, Devine, \& Prince, 2002). Delbaere et al., (2004) examined this issue and found a significant, but relatively weak, association between activity avoidance and falls. However, Hadjistavropoulos et al., (2007) have challenged traditional conceptualizations of the fear of falling/falls efficacy-avoidancefalls cycle. These authors conducted a 6-month longitudinal study of older community 
dwelling adults and found that falls efficacy (measured by the ABC and the FES) was a predictor of falls whereas activity avoidance was not. Fear of falling (measured by the SAFE) was also a significant predictor of falls but its contribution became non-significant when the FES and $A B C$ were entered into the equation (likely because of the SAFE's shared variance with the falls efficacy measures). Hadjistavropoulos et al. (2007) argued that this finding does not support the traditional fear avoidance conceptualizations of the relationship between falls and fear of falling and presented two alternative mechanisms (aside from avoidance and deconditioning) that could explain the association between falls and fear of falling. The first of these mechanisms focuses on anxiety as having a negative impact on balance performance. The second mechanism is based on the idea that fear of falling and reduced falls efficacy may be reflective of realistic appraisals of one's own physical capabilities and an accurate estimation of risk. We consider these two mechanisms below.

Alternative Explanations of the Relationship Between

Fear of Falling and with Falls

In considering alternative conceptualizations of the relationship between fear of falling and falls efficacy with falls, we ask a series of basic questions:

Can fear and anxiety have a direct influence on balance performance?: An important question is whether it is even necessary to use activity avoidance as a central and key mediator in the relationship between fear and falls. If fear and anxiety have a direct negative effect on balance performance, it may be unnecessary to use avoidance as a key central mediator. In other words, in contrast to the traditional conceptualization of level falls efficacy or fear of falling $\rightarrow$ avoidance $\rightarrow$ deconditioning $\rightarrow$ balance 
performance $\rightarrow$ falls, the alternative explanation would be fear and anxiety $\rightarrow$ balance performance $\rightarrow$ falls.

In a series of experimental studies involving older adults, anxiety levels were manipulated by elevating the participants at different heights. Carpenter et al. found that anxiety could result in a stiffening strategy at the ankle joint (Carpenter, Frank, Adkin, Paton, \& Allum, 2004; Carpenter, Frank, \& Silcher, 1999; Carpenter, Frank, Silcher, \& Peysar, 2001), which could affect the ability to adjust body position when exposed to a potential fall. Additionally, anxiety has also been related to a protective strategy while walking, by reducing speed and step length (Delbaere et al., 2009; Maki, 1997), resulting in reduced walking stability (Latt, Menz, Fung, \& Lord, 2008; Menz, Lord, \& Fitzpatrick, 2007), and therefore, increased falls risk (Delbaere et al., 2009). Interestingly, not only inappropriate high fear of falling may result in worse performance during dynamic balance tests, but inappropriate low fear seems to lead to overrating one's capacities (Delbaere, Crombez, Van Den Noortgate, Willems, \& Cambier, 2006). While these studies were conducted in controlled laboratory settings, they do support the view that people who are anxious about falling may not be able to maintain balance as well as those who are not afraid of falling. In answering the key question addressed in this section, it does appear that anxiety can have a direct negative effect on an individual's ability to maintain balance.

Can a low falls efficacy be reflective of an accurate appraisal of one's balance capabilities and fall risk? If low falls efficacy is reflective of an accurate appraisal of one's own balance capabilities and fall risk, the relationship between balance confidence and falls could be explained in the absence of avoidance as a mediator. It 
has been suggested that people who are afraid of falling may have this fear (and related falls efficacy) as a result of a realistic appraisal of their difficulties in maintaining their balance. If this were the case, from a clinical standpoint, it would be important to determine whether a person's fear of falling is excessive in light of his or her physical limitations (Hadjistavropoulos et al., 2007). If the fear is excessive, it would be an appropriate target for intervention. On the other hand, if the fear (or reduced falls efficacy) reflects a realistic appraisal of one's functional limitations, then the clinical focus should be on suitable rehabilitation. The extent to which balance confidence reflects realistic appraisals has not been adequately researched. Interestingly, in a prospective cohort study examining level of concern about the possibility of falls, it was found that higher levels of concern about falling did not result in a reduced amount of planned exercise (Delbaere, Close, Brodaty, Sachdev, \& Lord, submitted). In people showing a disparity between concern about the possibility of a fall and balance abilities, high levels of fear of falling were related to future falls. This relationship was explained mainly through psychological pathways such as depression. In the same group of people, low levels of concern about the possibility of a fall were protective for falling through a positive outlook on life, and maintained physical activity and community participation. This supports our view that the relationship between balance confidence and falls does not need activity avoidance as a mediator.

\section{Classical and Operant Conditioning in Fear of Falling}

Prior to re-considering a model of fear of falling in light of the responses to the questions that we reviewed, we noted that there has been minimal discussion in the literature on the psychological origins of fear of falling. Fear of falling may reflect a 
realistic appraisal of reduced functional abilities and consequent increased risk of suffering a fall and fall injuries. Such a fear may also result from a first hand experience, as suggested by Howland et al. (1998). The Howland et al. finding that the degree of fear of falling (measured by a direct question about fear of falling) is associated with the number and seriousness of the falls experienced is consistent with classical conditioning theory. That is, the association of a neutral activity such as walking or climbing stairs with a painful injurious fall could cause the neutral activity to become anxiety provoking. Consistent with Mowrer's two factor theory (Mowrer, 1939; 1960), operant factors would also operate in the fear-avoidance cycle. That is, avoidance of activity would lead to temporary reductions in anxiety because fear would be less likely to be experienced when an anxiety-provoking activity is avoided. While effective in the short term, needless restriction of activities can strengthen maladaptive fall beliefs and increase the likelihood that future falls will be interpreted catastrophically. This fearbased psychological state. designed to protect the individual from falling, may then promote additional fall-related fear.

Although classical conditioning and operant processes are likely frequent contributors to the fear avoidance cycle, fear can also be the result of vicarious learning and cognitive processes. With respect to the former, fear of falling could also result from a second-hand experience such as witnessing a fall (Bandura, 1977; Rachman, 1998). From a cognitive standpoint, beliefs (Rachman, 1998) about one's fall risk would also have an impact on level of fear. Such beliefs would impact fear regardless of whether they are accurate or inaccurate. In the case of excessive fear, avoidance of activity would also prevent the individual from accumulating evidence that would disconfirm 
their inaccurate belief about the risks associated with day-to-day activities. This tendency towards excessive fear could also arise as a function of predispositional factors such as neurotic personality traits (Mann, Birks, Hall, Torgerson, \& Watt, 2006), anxiety sensitivity, or negative affectivity (Delbaere et al., submitted). With these considerations in mind we reconceptualized the falls-avoidance cycle.

\section{A Multi-Factorial Causation Model of Falls and Fear}

Figure 2 presents a new proposed conceptualization of the relationship between fear of falling and falls for older persons residing in the community. We suggest that fear of falling originates from an individual's appraisal of his or her own abilities to maintain balance in combination with other contributors such as falls history or beliefs that a person holds regarding falls. An individual's appraisal of his or her own abilities to maintain balance is viewed as being related to balance performance and previous falls but as not playing a causal role (the bi-directional arrows imply association but not causality). The model treats falls efficacy and fear of falling as distinct constructs. Moreover, the relationship between fear of falling and falls is partially mediated by falls efficacy and balance performance. This mediated relationship would be consistent with the findings of $\mathrm{Li}$ et al. (2002) and emphasizes the point that fear of falling and falls efficacy should not be used interchangeably. Nonetheless, the model also recognizes that falls efficacy can also affect the level of fear of falling. Activity avoidance is included in the model and is predicted by both fear of falling and balance confidence. Other predictors of activity avoidance (e.g., degree of social support) will also need to be considered (Howland et al., 1998). Nonetheless, the direct relation between activity avoidance and falls is uncertain, in light of inconsistencies in the literature about its 
relationship to falls (Delbaere et al., 2004; Hadjistavropoulos et al., 2007), and is, therefore, represented with a dotted line.

This new conceptualization, which is limited in scope in that it is only aimed to explain the role of fear and falls efficacy in fall risk (i.e., it is not intended to be a global model of fall prediction), should be subject to further study and has the potential of serving an important function in the literature by encouraging researchers to separate fear of falling from balance confidence. Moreover, to our knowledge it represents the first systematic attempt to incorporate what has been known in the literature of fear of falls and falls efficacy in a model that goes beyond earlier, perhaps oversimplified, conceptualizations.

\section{Conclusion and Future Directions}

In conclusion, the widely accepted traditional fear-avoidance model of falls has not been adequately supported. In fact, there is increasing support for alternative conceptualizations based on kinesiology and gait research. We have attempted to integrate such research with psychological conceptualizations and have proposed an alternative model. Aspects of the alternative model are supported by the literature but the model must be tested as a whole.

As we are calling for more research in the area of fear of falling, we recognize that most readers are likely to assume that this research will necessarily involve older adults. The question as to whether fear of falling and falls efficacy are primarily a concern of older persons is an empirical one. In fact, research suggests that the constructs are not necessarily age-specific. When examining falls efficacy in a community sample, Williams et al (2005) demonstrated, not surprisingly, that falls 
efficacy was significantly lower among older adults as compared to younger persons. However, Martin et al. (2005) compared several age groups of physiotherapy outpatients with respect to falls efficacy and found no age differences. As such, it appears that although reduced falls efficacy is largely an age-specific concern in the general population, it is not age-specific among patients with musculoskeletal problems. In light of this evidence, it would be useful to extend fear falling and/or falls efficacy research to younger populations with injuries or other gait and/or mobility problems. Important research directions could also have a clinical focus. Examining the predictive ability of comprehensively-measured fear of falling (i.e., assessing its behavioral, cognitive and physiological components) in community studies would be a fruitful area of future study. Moreover, clinicians should be acutely aware that many patients with elevated fear of falling may be accurately estimating their level of fall risk. The accuracy level should be assessed and taken into account when attempting to help patients optimize the quality of their lives. It would also be important to stress that, regardless of patient appraisal accuracy, low levels of falls efficacy (and associated fear of falling) can further increase fall risk (e.g., Delbaere et al., submitted) possibly because of the direct negative effect of anxiety and fear on balance performance (Carpenter et al., 2006; Delbaere et al., 2009).

Theoretically and clinically driven investigations in the area of falls is increasingly important considering the booming aging demographic and the increased risk of falls that occurs with aging and frailty. As such, we hope that we have provided a novel way of examining fear-avoidance in the context of falls that can help guide future research in the area while clarifying the interrelationships among the constructs of interest. 


\section{References}

Arfken, C. L., Lach, H. W., Birge, S. J., \& Miller, J. P. (1994). The prevalence and correlates of fear of falling in elderly persons living in the community. American Journal of Public Health, 84, 565-570.

Asmundson, G. J., \& Taylor, S. (1996). Role of anxiety sensitivity in pain-related fear and avoidance. Journal of Behavioral Medicine, 19, 577-586.

Asmundson, G. J. G., Vlaeyen, J., \& Crombez, G. (Eds.). (2004). Understanding and treating fear of pain. New York, NY: Oxford University Press.

Asmundson, G. J. G., \& Wright, K. (2004). Biopsychosocial approaches to pain. In T. Hadjistavropoulos \& K. D. Craig (Eds.), Pain: Psychological perspectives (pp. 3587). Mahwah: Lawrence Erlbaum Associates.

Austin, N., Devine, A., Dick, I., Prince, R., \& Bruce, D. (2007). Fear of falling in older women: A longitudinal study of incidence, persistence, and predictors. Journal of the American Geriatrics Society, 55, 1598-1603.

Bandura, A. (1977). Social learning theory. New York, NY: General Learning Press.

Bandura, A. (1986). Social foundations of thought and action: A social cognitive theory. Englewood Cliffs, NJ: Prentice-Hall.

Bandura, A. (1994). Self-efficacy. In V. S. Ramachaudran (Ed.), Encyclopedia of human behavior. New York: Academic Press. (Vol. 4, pp. 71-81). San Diego: Academic Press.

Barlow, D. H. (Ed.). (2008). Clinical handbook of psychological disorders: A step by step treatment manual. New York, NY: Guilford Press.

Bhala, R. P., O'Donnell, J., \& Thoppil, E. (1982). Ptophobia. Phobic fear of falling and its clinical management. Physical Therapy, 62, 187-190.

Bruce, D. G., Devine, A., \& Prince, R. L. (2002). Recreational physical activity levels in healthy older women: the importance of fear of falling. Journal of the American Geriatrics Society, 50, 84-89.

Brummel-Smith, K. (1989). Falls in the aged. Primary Care; Clinics in Office Practice, 16, 377-393.

Buer, N., \& Linton, S. J. (2002). Fear-avoidance beliefs and catastrophizing: occurrence and risk factor in back pain and ADL in the general population. Pain, 99, 485491.

Butki, B. D., Rudolph, D. L., \& Jacobsen, H. (2001). Self-efficacy, state anxiety, and cortisol responses to treadmill running. Perceptual and Motor Skills, 92, 11291138.

Carpenter, M. G., Adkin, A. L., Brawley, L. R., \& Frank, J. S. (2006). Postural, physiological and psychological reactions to challenging balance: Does age make a difference? Age and Ageing, 35, 298-303.

Carpenter, M. G., Frank, J. S., Adkin, A. L., Paton, A., \& Allum, J. H. J. (2004). Influence of postural anxiety on postural reactions to multi-directional surface rotations. Journal of Neurophysiology, 92, 3255-3265.

Carpenter, M. G., Frank, J. S., \& Silcher, C. P. (1999). Surface height effects on postural control: A hypothesis for a stiffness strategy for stance. Journal of Vestibular Research-Equilibrium \& Orientation, 9, 277-286. 
Carpenter, M. G., Frank, J. S. a., Silcher, C. P., \& Peysar, G. W. (2001). The influence of postural threat on the control of upright stance. Experimental Brain Research, $138,210$.

Cumming, R. G., Salkeld, G., Thomas, M., \& Szonyi, G. (2000). Prospective study of the impact of fear of falling on activities of daily living, SF-36 scores, and nursing home admission. Journals of Gerontology Series a-Biological Sciences and Medical Sciences, 55, M299-M305.

Delbaere, K., Close, J., Brodaty, Sachdev, \& Lord, S. (submitted). Fall Risk and Fear of Falling in Older People: The Vigorous, The Anxious, The Stoic and The Aware.

Delbaere, K., Close, J., Mikolaizak, S., Sachdev, Perminder, S., Brodaty, H., et al. (in press). The Falls Eficacy Scale International (FES-I). A Compreshensive Longitudinal Validation Study. Age and Ageing.

Delbaere, K., Crombez, G., Van Den Noortgate, N., Willems, T., \& Cambier, D. (2006). The risk of being fearful or fearless in older people: An empirical validation. Disability and Rehabilitation, 28, 751-756.

Delbaere, K., Crombez, G., Vanderstraeten, G., Willems, T., \& Cambier, D. (2004). Fear-related avoidance of activities, falls and physical frailty. A prospective community-based cohort study. Age and Ageing, 33, 368-373.

Delbaere, K., Sturnieks, D. L., Crombez, G., \& Lord, S. R. (2009). Concern about falls elicits changes in gait parameters in conditions of postural threat in older people. Journals of Gerontology - Series A Biological Sciences and Medical Sciences, 64, 237-242.

Denison, E., Asenlof, P., \& Lindberg, P. (2004). Self-efficacy, fear avoidance, and pain intensity as predictors of disability in subacute and chronic musculoskeletal pain patients in primary health care. Pain, 111, 245-252.

Fessel, K. D., \& Nevitt, M. C. (1997). Correlates of fear of falling and activity limitation among persons with rheumatoid arthritis. Arthritis Care and Research, 10, 222228.

Fletcher, P. C., \& Hirdes, J. P. (2004). Restriction in activity associated with fear of falling among community-based seniors using home care services. Age and Ageing, 33, 273-279.

Friedman, S. M., Munoz, B., West, S. K., Rubin, G. S., \& Fried, L. P. (2002). Falls and fear of falling: Which comes first? A longitudinal prediction model suggests strategies for primary and secondary prevention. Journal of the American Geriatrics Society, 50, 1329-1335.

Hadjistavropoulos, T., Martin, R. R., Sharpe, D., Lints-Martindale, A. C., McCreary, D. R., \& Asmundson, G. J. G. (2007). A longitudinal investigation of fear of falling, fear of pain, and activity avoidance in community dwelling older adults. $J$ Aging Health, 19, 965-984.

Hawk, C., Hyland, J. K., Rupert, R., Colonvega, M., \& Hall, S. (2006). Assessment of balance and risk for falls in a sample of community-dwelling adults aged 65 and older. Chiropractic and Osteopathy, 14, 3.

Hill, K. D., Schwarz, J. A., Kalogeropoulos, A. J., \& Gibson, S. J. (1996). Fear of falling revisited. Archives of Physical Medicine and Rehabilitation, 77, 1025-1029. 
Hotchkiss, A., Fisher, A., Robertson, R., Ruttencutter, A., Schuffert, J., \& Barker, D. B. (2004). Convergent and predictive validity of three scales related to falls in the elderly. American Journal of Occupational Therapy, 58, 100-103.

Howland, J., Lachman, M. E., Peterson, E. W., Cote, J., Kasten, L., \& Jette, A. (1998). Covariates of fear of falling and associated activity curtailment. Gerontologist, 38, 549-555.

Howland, J., Peterson, E. W., Levin, W. C., Fried, L., Pordon, D., \& Bak, S. (1993). Fear of falling among the community-dwelling elderly. Journal of Aging and Health, 5, 229-243.

Jorstad, E. C., Hauer, K., Becker, C., \& Lamb, S. E. (2005). Measuring the psychological outcomes of falling: A systematic review. Journal of the American Geriatrics Society, 53, 501-510.

Kellogg International Work Group on the Prevention of Falls by the Elderly (1987). The prevention of falls later in life. A report of the Kellogg International Work Group on the Prevention of Falls by the Elderly. Danish Medical Bulletin, 34, 1-24.

Lachman, M. E., Howland, J., Tennstedt, S., Jette, A., Assmann, S., \& Peterson, E. W. (1998). Fear of falling and activity restriction: The Survey of Activities and Fear of Falling in the Elderly (SAFE). Journals of Gerontology Series B-Psychological Sciences and Social Sciences, 53, P43-P50.

Lamb, S. E., Jorstad-Stein, E. C., Hauer, K., Becker, C., \& Preventon of Falls Network Europe and Outcomes Consensus Group (2005). Development of a common outcome data set for fall injury prevention trials: The Prevention of Falls Network Europe consensus. Journal of the American Geriatrics Society, 53, 1618-1622.

Latt, M. D., Menz, H. B., Fung, V. S., \& Lord, S. R. (2008). Walking speed, cadence and step length are selected to optimize the stability of head and pelvis accelerations. Experimental Brain Research, 184, 201-209.

Lawrence, R. H., Tennstedt, S. L., Kasten, L. E., Shih, J., Howland, J., \& Jette, A. M. (1998). Intensity and correlates of fear of falling and hurting oneself in the next year - Baseline findings from a Roybal center fear of falling intervention. Journal of Aging and Health, 10, 267-286.

Legters, K. (2002). Fear of falling. Physical Therapy, 82, 264-272.

Lethem, J., Slade, P. D., Troup, J. D., \& Bentley, G. (1983). Outline of a Fear-Avoidance Model of exaggerated pain perception--I. Behav Res Ther, 21, 401-408.

Li, F. Z., Fisher, K. J., Harmer, P., McAuley, E., \& Wilson, N. L. (2003). Fear of falling in elderly persons: Association with falls, functional ability, and quality of life. Journals of Gerontology Series B-Psychological Sciences and Social Sciences, 58, P283-P290.

Li, F. Z., McAuley, E., Fisher, K. J., Harmer, P., Chaumeton, N., \& Wilson, N. L. (2002). Self-efficacy as a mediator between fear of falling and functional ability in the elderly. Journal of Aging and Health, 14, 452-466.

Maki, B. E. (1997). Gait changes in older adults: Predictors of falls or indicators of fear? Journal of the American Geriatrics Society, 45, 313-320.

Maki, B. E., Holliday, P. J., \& Topper, A. K. (1991). Fear of Falling and Postural Performance in the Elderly. Journals of Gerontology, 46, M123-M131. 
Mann, R., Birks, Y., Hall, J., Torgerson, D., \& Watt, I. (2006). Exploring the relationship between fear of falling and neuroticism: a cross-sectional study in communitydwelling women over 70. Age and Ageing, 35, 143-147.

Martin, R. R., Hadjistavropoulos, T., \& McCreary, D. R. (2005). Fear of pain and fear of falling among younger and older adults with musculoskeletal pain conditions. Pain Research and Management, 10, 211-219.

Menz, H. B., Lord, S. R., \& Fitzpatrick, R. C. (2007). A structural equation model relating impaired sensorimotor function, fear of falling and gait patterns in older people. Gait and Posture, 25, 243-249.

Moore, D. S., \& Ellis, R. (2008). Measurement of fall-related psychological constructs among independent-living older adults: a review of the research literature. Aging and Mental Health, 12, 684-699.

Mowrer, O. H. (1939). Stimulus reponse theory of anxiety. Psychological Review, 46.

Mowrer, O. H. (1960). Learning theory and behavior. New York, NY: Wiley.

Murphy, J., \& Isaacs, B. (1982). The Post-Fall Syndrome - a Study of 36 Elderly Patients. Gerontology, 28, 265-270.

Murphy, S. L., Dubin, J. A., \& Gill, T. M. (2003). The development of fear of falling among community-living older women: Predisposing factors and subsequent fall events. Journals of Gerontology Series a-Biological Sciences and Medical Sciences, 58, 943-947.

Murphy, S. L., Williams, C. S., \& Gill, T. M. (2002). Characteristics associated with fear of falling and activity restriction in community-living older persons. Journal of the American Geriatrics Society, 50, 516-520.

Myers, A. M., Fletcher, P. C., Myers, A. H., \& Sherk, W. (1998). Discriminative and evaluative properties of the Activities-specific Balance Confidence (ABC) Scale. Journals of Gerontology. Series A, Biological Sciences \& Medical Sciences. 53A, 4.

Norton, P. J., \& Asmundson, G. J. G. (2003). Amending the fear-avoidance model of chronic pain: What is the role of physiological arousal? Behav Res Ther, 34, 1730.

Petrella, R. J., Payne, M., Myers, A., Overend, T., \& Chesworth, P. (2000). Physical function and fear of falling after hip fracture rehabilitation in the elderly. American Journal of Physical Medicine \& Rehabilitation, 79, 154-160.

Rachman, S. (1978). Fear and courage. San Francisco: Freeman.

Rachman, S. (1998). Anxiety. East Sussex UK: Psychology Press.

Rice, D. P., \& MacKenzie, E. J. (1989). Cost of injury in the United States: a Report to Congress. San Francisco: Institute for Health and Ageing, University of California.

Rubenstein, L. Z. (2006). Falls in older people: Epidemiology, risk factors and strategies for prevention. Age and Ageing, 35, ii37-ii42.

Stevens, J. A., Mack, K. A., Paulozzi, L. J., \& Ballesteros, M. F. (2006). Self-reported falls and fall-related injuries among persons aged greater than or equal to 65 years - United States. Journal of Safety Research, 39, 345-349.

Tinetti, M. E., Deleon, C. F. M., Doucette, J. T., \& Baker, D. I. (1994). Fear of Falling and Fall-Related Efficacy in Relationship to Functioning among CommunityLiving Elders. Journals of Gerontology, 49, M140-M147. 
Tinetti, M. E., \& Powell, L. (1993). Fear of Falling and Low Self-Efficacy - a Cause of Dependence in Elderly Persons. Journals of Gerontology, 48, 35-38.

Tinetti, M. E., Richman, D., \& Powell, L. (1990). Falls Efficacy as a Measure of Fear of Falling. Journals of Gerontology, 45, P239-P243.

Vellas, B., Wayne, S., Romero, L., Baumgartner, R., \& Garry, P. (1997). Fear of falling and restriction of mobility in elderly fallers. Age Ageing, 26, 189-193.

Verghese, J., Holtzer, R., Lipton, R. B., \& Wang, C. (2009). Quantitative gait markers and incident fall risk in older adults. J Gerontol A Biol Sci Med Sci, 64, 896-901.

Vlaeyen, J. W. S., \& Linton, S. J. (2000). Fear-avoidance and its consequences in chronic musculoskeletal pain: a state of the art. Pain, 85, 317-332.

Williams, J., Hadjistavropoulos, T., \& Asmundson, G. J. G. (2005). The effects of age and fear of pain on attentional and memory biases relating to pain and falls. Anxiety Stress Coping, 18, 53-69.

Wright, B. A., Aizenstein, S., Vogler, G., Rowe, M., \& Miller, C. (1990). Frequent fallers: Leading groups to identify psychological factors. Journal of Gerontological Nursing, 16, 15-19.

Yardley, L., Beyer, N., Hauer, K., Kempen, G., Piot-Ziegler, C., \& Todd, C. (2005). Development and initial validation of the Falls Efficacy Scale-International (FESI). Age and Ageing, 34, 614-619.

Zijlstra, G. A. R., Haastregt, J. C. M., van Eijk, J. T. M., Rossum, E. V., Stalenhoef, P. A., \& Kempen, G. I. J. M. (2007). Prevalence and correlates of fear of falling, and associated avoidance of activity in the general population of community-living older people. Age and Ageing, 36, 304-309. 


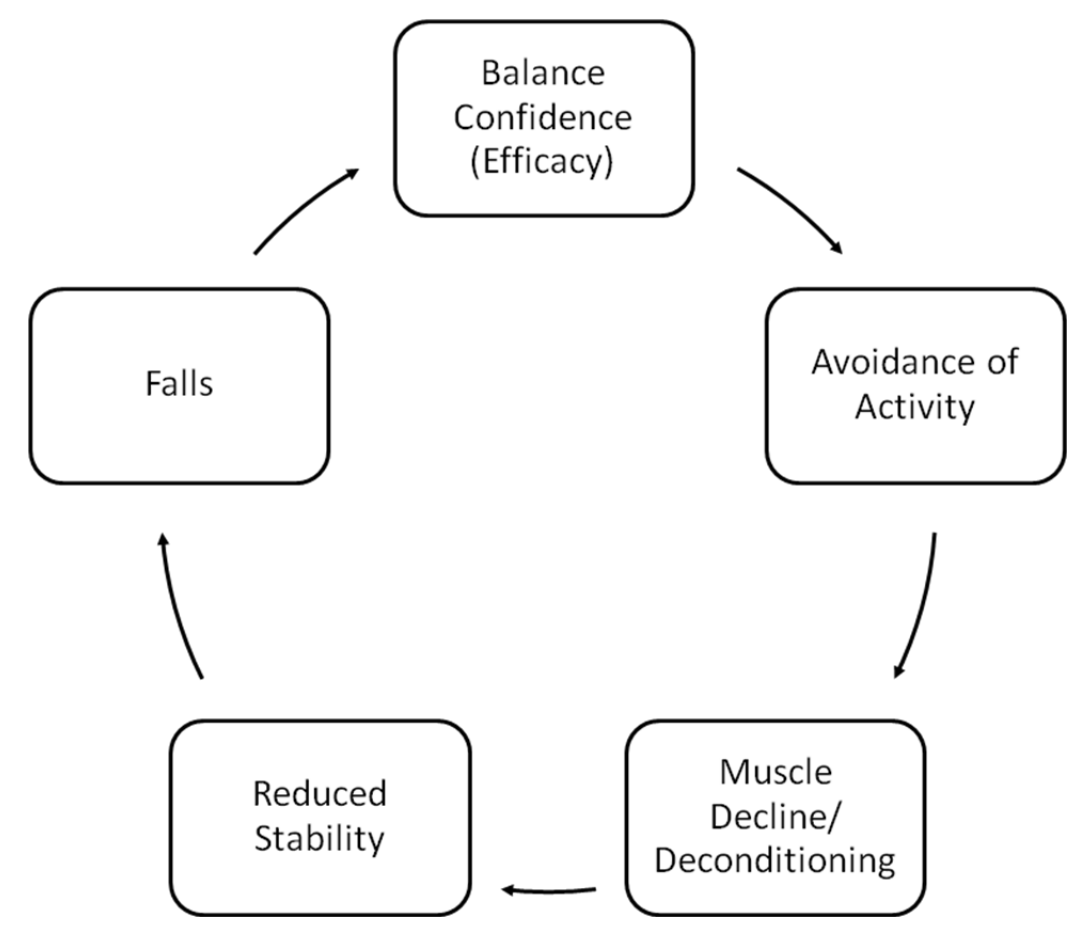




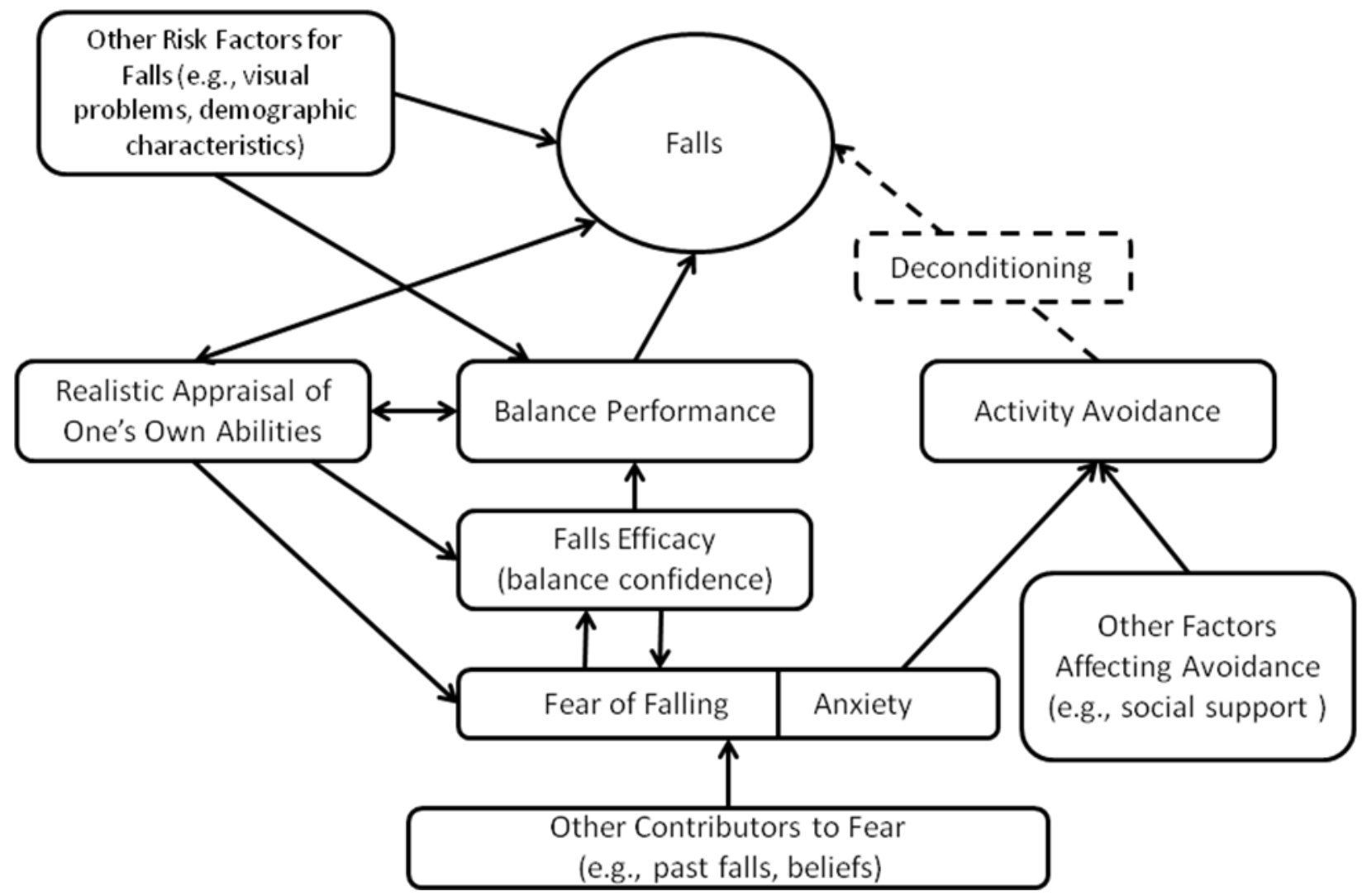




\section{Figure Captions}

Figure 1: Traditional conceptualizations of fear of falling

Figure 2: Reconceptualizing fear of falling 